\title{
Patent ductus arteriosus associated with pulmonary hypertension and desaturation
}

\author{
Anant Khositseth, Suthep Wanitkun \\ Department of Pediatrics, Faculty of Medicine, Ramathibodi Hospital, \\ Mahidol University, Bangkok, Thailand
}

\begin{abstract}
We present the cases of three children with patent ductus arteriosus (PDA), pulmonary arterial hypertension (PAH), and desaturation. One of them had desaturation associated with atrial septal defect (ASD). His ASD, PAH, and desaturation improved after successful device closure of the PDA. The other two had desaturation associated with Down syndrome. One had desaturation only at room air oxygen (21\% oxygen) but well saturated with $100 \%$ oxygen, subsequently underwent successful device closure of the PDA. The other had experienced desaturation at a younger age but spontaneously recovered when he was older, following attempted device closure of the PDA, with late embolization of the device. (Cardiol J 2012; 19, 5: 543-546)
\end{abstract}

Key words: congenital heart disease, pulmonary vascular resistance

\section{Introduction}

Patent ductus arteriosus (PDA) is a common congenital heart disease. Increased pulmonary pressure causing pulmonary arterial hypertension $(\mathrm{PAH})$ associated with PDA is secondary to either increased pulmonary blood flow (PBF) or increased pulmonary vascular resistance (PVR) [1]. If $\mathrm{PAH}$ is solely caused by increased PBF, PAH will be completely resolved after PDA closure. If $\mathrm{PAH}$ is associated with high PVR, it may remain after PDA closure. PAH is defined as mean pulmonary artery pressure $(\mathrm{PAP})>25 \mathrm{~mm} \mathrm{Hg}$ at rest [2]. We report one case of PDA associated with PAH, atrial septal defect (ASD), and desaturation, and two cases of Down syndrome and PDA associated with PAH and desaturation.

\section{Case reports}

\section{Case 1}

A two year-old boy presented with a history of cyanosis when crying and dyspnea on exertion, with poor weight gain since the age of seven months. Physical examination revealed: weight $10 \mathrm{~kg}$ $\left(3^{\text {rd }}-10^{\text {th }}\right.$ percentile $)$, height $78 \mathrm{~cm}\left(<3^{\text {rd }}\right.$ percentile $)$, oxygen saturation $\left(\mathrm{SaO}_{2}\right) 91 \%$, loud $\mathrm{P} 2$, and grade $3 / 6$ systolic ejection murmur (SEM) at the left upper sternal border (LUSB). Chest film, electrocardiogram (ECG), and echocardiography findings are summarized in Table 1 . In addition, he also had ASD, secundum type, $8 \mathrm{~mm}$ in diameter with bidirectional shunting. Cardiac catheterization was performed (Table 2). We decided to close the PDA using an 8/6 Amplatzer ductal occluder (ADO) $\left(\mathrm{AGA}^{\mathrm{TM}}\right.$ Medical Corporation) using a previously described technique [3, 4]. At three-month follow-up, we found clinical improvement and his echocardiography demonstrated closure of the ASD, no residual PDA, mild tricuspid regurgitation (TR), and estimated systolic PAP equal to $40 \mathrm{~mm} \mathrm{Hg}$. $\mathrm{His}^{\mathrm{SaO}_{2}}$ had returned to $97 \%$ (Fig. 1).

\section{Case 2}

A nine year-old boy with Down syndrome presented with a history of dyspnea on exertion and

Address for correspondence: Anant Khositseth, MD, Department of Pediatrics, Faculty of Medicine Ramathibodi Hospital, Mahidol University, 270 Rama VI Road, Ratchathewi, Bangkok 10400, Thailand, tel: 662-201-1685, fax: 662-201-1850, e-mail:khositseth@gmail.com

Received: 16.09.2011 Accepted: 19.10.2011 
Table 1. Summary of chest film, electrocardiography, and echocardiography in each patient.

\begin{tabular}{|c|c|c|c|}
\hline Investigations & Patient 1 & Patient 2 & Patient 3 \\
\hline Chest film & CTR 0.56; $\uparrow$ PBF & CTR 0.55; $\uparrow$ PBF & CTR 0.62; $\uparrow$ PBF \\
\hline Electrocardiography & $\begin{array}{c}\text { RAD; } \mathrm{QRS} \text { axis }+150^{\circ} ; \\
\text { RVH }\end{array}$ & $\begin{array}{c}\text { Normal axis; QRS axis }+60^{\circ} \text {; } \\
\text { LVH }\end{array}$ & $\begin{array}{c}\text { RAD; } \text { QRS axis }+105^{\circ} ; \\
\text { LVH, RVH }\end{array}$ \\
\hline \multicolumn{4}{|l|}{ Echocardiography: } \\
\hline PDA size [mm] & $5-6$ & $7-8$ & 12 \\
\hline LA/Ao ratio & 1.5 & 1.1 & 1.2 \\
\hline TR severity & Mild & Mild & Mild to moderate \\
\hline TR PG [mm Hg] & 45 & 50 & 86 \\
\hline
\end{tabular}

Ao - aorta; CTR — cardio-thoracic ratio; LA — left atrium; LVH — left ventricular hypertrophy; PBF — pulmonary blood flow; PG — pressure gradient; RAD — right axis deviation; RVH — right ventricular hypertrophy; TR — tricuspid regurgitation

Table 2. Summary of cardiac catheterization data in each patient.

\begin{tabular}{|c|c|c|c|c|c|c|}
\hline \multirow[t]{3}{*}{ Parameters } & \multirow{3}{*}{$\begin{array}{c}\text { Patient } 1 \\
21 \% \mathrm{O}_{2} \\
2 \mathrm{y}\end{array}$} & \multicolumn{2}{|c|}{ Patient 2} & \multirow{2}{*}{\multicolumn{3}{|c|}{$\frac{\text { Patient } 3}{21 \% \mathrm{O}_{2}}$}} \\
\hline & & \multirow{2}{*}{$\frac{21 \% \mathrm{O}_{2}}{9 \mathrm{y}}$} & \multirow{2}{*}{$\frac{100 \% \mathrm{O}_{2}}{9 \mathrm{y}}$} & & & \\
\hline & & & & 9 mo & $9 y$ & $13 y$ \\
\hline SVC sat (\%) & 69 & 72 & 91 & 52 & 52 & 51 \\
\hline FA sat (\%) & 91 & $89 *$ & $100^{\dagger}$ & 65 & 96 & 98 \\
\hline PA sat (\%) & 86 & 80 & $99^{\ddagger}$ & 56 & 86 & 88 \\
\hline PAP [mm Hg] & $57 / 32(43)$ & 70/39 (55) & $57 / 25(40)$ & 69/46 (53) & $71 / 38(52)$ & $82 / 39(58)$ \\
\hline QP/QS & 1.8 & 1.1 & 7.0 & 0.28 & 2.7 & 4.7 \\
\hline PVR [Wood units] & 4.2 & 6.1 & 0.9 & 25.5 & 5.7 & 4.2 \\
\hline $\mathrm{AoP}[\mathrm{mm} \mathrm{Hg}]$ & $73 / 40(54)$ & $104 / 53(70)$ & $107 / 48(71)$ & $74 / 46(57)$ & $113 / 49(70)$ & $100 / 69$ (85) \\
\hline Mean PAP/AoP (\%) & 80 & 79 & 56 & 93 & 74 & 68 \\
\hline PDA diameter Ao/PA ends [mm] & $6.3 / 4.2$ & \multicolumn{2}{|c|}{$8.0 / 6.2$} & $5 / 5$ & $12 / 12$ & $12 / 12$ \\
\hline Size of ADO & $8 / 6$ & \multicolumn{2}{|c|}{$12 / 10$} & - & - & $16 / 14$ \\
\hline
\end{tabular}

*At room air oxygen $(21 \%)$ and after sedation. $\mathrm{His} \mathrm{PCO}_{2}$ was increased to $55 \mathrm{~mm} \mathrm{Hg}$ with pH 7.3. His oxygen saturation in the ascending aorta was $96 \%$ compared to $89 \%$ in the femoral artery (differential cyanosis); ${ }^{+} \mathrm{PaO}_{2} 404 \mathrm{~mm} \mathrm{Hg}$; ${ }^{7} \mathrm{PaO}_{2} 210 \mathrm{~mm} \mathrm{Hg}$; ADO - Amplatzer ductal occluder; Ao - aorta; AoP - aortic pressure; FA — femoral artery; $\mathrm{O}_{2}$ - oxygen; QP/OS — pulmonary blood flow/systemic blood flow; PA — pulmonary artery;

PAP — pulmonary arterial pressure; PDA — patent ductus arteriosus; PVR - pulmonary vascular resistance; SVC — superior vena cava

recurrent pneumonia. He had been diagnosed with a large PDA at the age of three years, but it was decided not to operate due to his Down syndrome. $\mathrm{He}$ was still on furosemide and digitalis. Physical examination revealed weight $15.4 \mathrm{~kg}\left(<3^{\text {rd }}\right.$ percentile), height $103 \mathrm{~cm}\left(<3^{\text {rd }}\right.$ percentile), $\mathrm{SaO}_{2} 100 \%$ (right hand) and 90\% (right foot), loud P2, and grade 3/6 SEM at LUSB. Chest film, ECG, and echocardiography findings are summarized in Table 1. Cardiac catheterization was performed (Table 2). At room air oxygen ( $21 \%$ oxygen), he had desaturation (femoral artery $\mathrm{SaO}_{2} 91 \%$ ). However, giving $100 \% \mathrm{O}_{2}$ eliminated his desaturation. We decided to close the PDA using a 12/10 ADO. At threemonth follow-up, we found clinical improvement and his echocardiography demonstrated no residual PDA, mild TR, and estimated systolic PAP equal to $40 \mathrm{~mm} \mathrm{Hg}$ (Fig. 2).

\section{Case 3}

A 13 year-old boy with Down syndrome presented with a known case of PDA. At the age of nine months, he was found to have desaturation $\left(\mathrm{SaO}_{2}\right.$ $70 \%$ ) and underwent cardiac catheterization (Table 2). He was conservatively followed due to the belief that the PDA was inoperable. He remained asymptomatic with improved $\mathrm{SaO}_{2}$ to $95 \%$. At the age of nine years, he underwent another cardiac catheterization (Table 2). Surgical closure of the PDA was discussed, but his parents decided against the surgery. He was then followed until he was 13 years old. Physical examination revealed: weight $25.4 \mathrm{~kg}$ $\left(<3^{\text {rd }}\right.$ percentile), height $131 \mathrm{~cm}\left(<3^{\text {rd }}\right.$ percentile), $\mathrm{SaO}_{2} 97 \%$, loud $\mathrm{P} 2$, and grade 2/6 SEM at LUSB. Chest film, ECG, and echocardiography findings are summarized in Table 1. Cardiac catheterization was performed (Table 2). After discussion with his pa- 


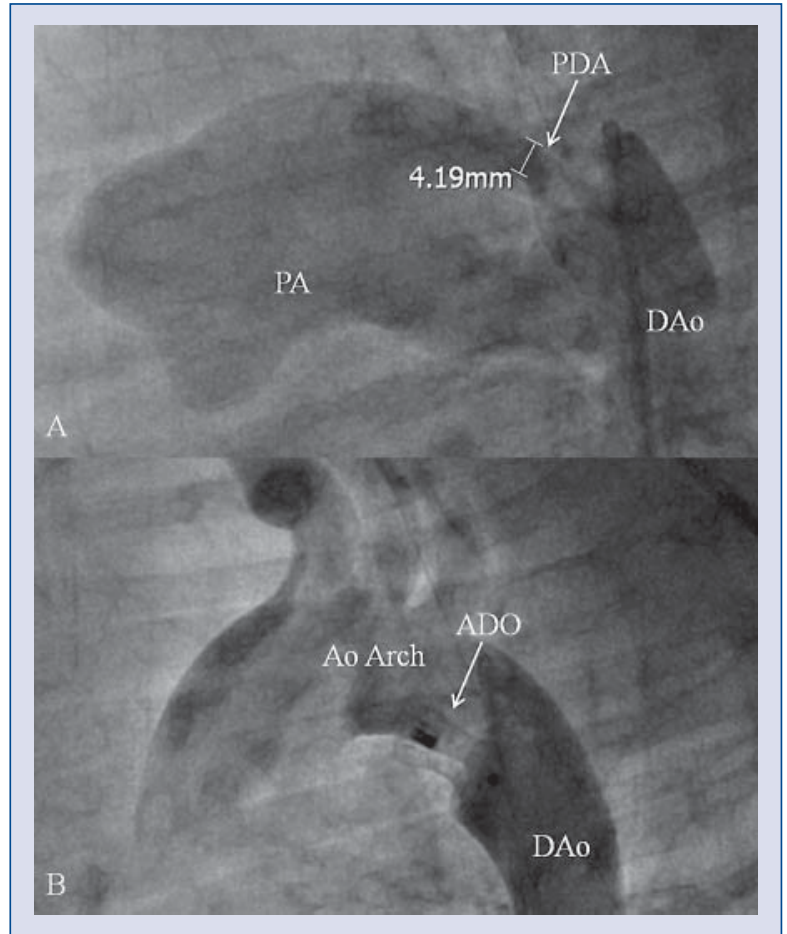

Figure 1. Angiography in the descending aorta (DAo) in patient 1 demonstrated contrast filled into pulmonary artery (PA) and size of patent ductus arteriosus (PDA) (A), and angiography after the Amplatzer ductal occlu$\operatorname{der}(A D O)$ demonstrated proper position of ADO in the PDA (B).

rents, we decided to close the PDA using a $16 / 14$ ADO. The systolic PAP after PDA device was decreased to $50 \mathrm{~mm} \mathrm{Hg}$. Echocardiography on day one after the procedure revealed the ADO device was in the proper position with a residual PDA, $3 \mathrm{~mm}$ in diameter, mild to moderate TR, and estimated systolic PAP equal to $55 \mathrm{~mm} \mathrm{Hg}$. However, at three-month follow-up, his echocardiography demonstrated large PDA with embolization of the ADO device into the descending aorta, mild to moderate TR, and estimated systolic PAP increased to $105 \mathrm{~mm} \mathrm{Hg}$. Cardiac catheterization was performed with attempted ADO device removal using a percutaneous snare. However, it was unsuccessful due to the difficulty of dislodging the ADO device from the abdominal aorta. The ADO device was then successfully removed surgically. We discussed with his parents the option of surgery but they have not yet decided (Fig. 3).

\section{Discussion}

A large PDA results in increased PBF and secondary PAH [5]. This leads to high PVR over time, but is unusual in children under two years. Case 1

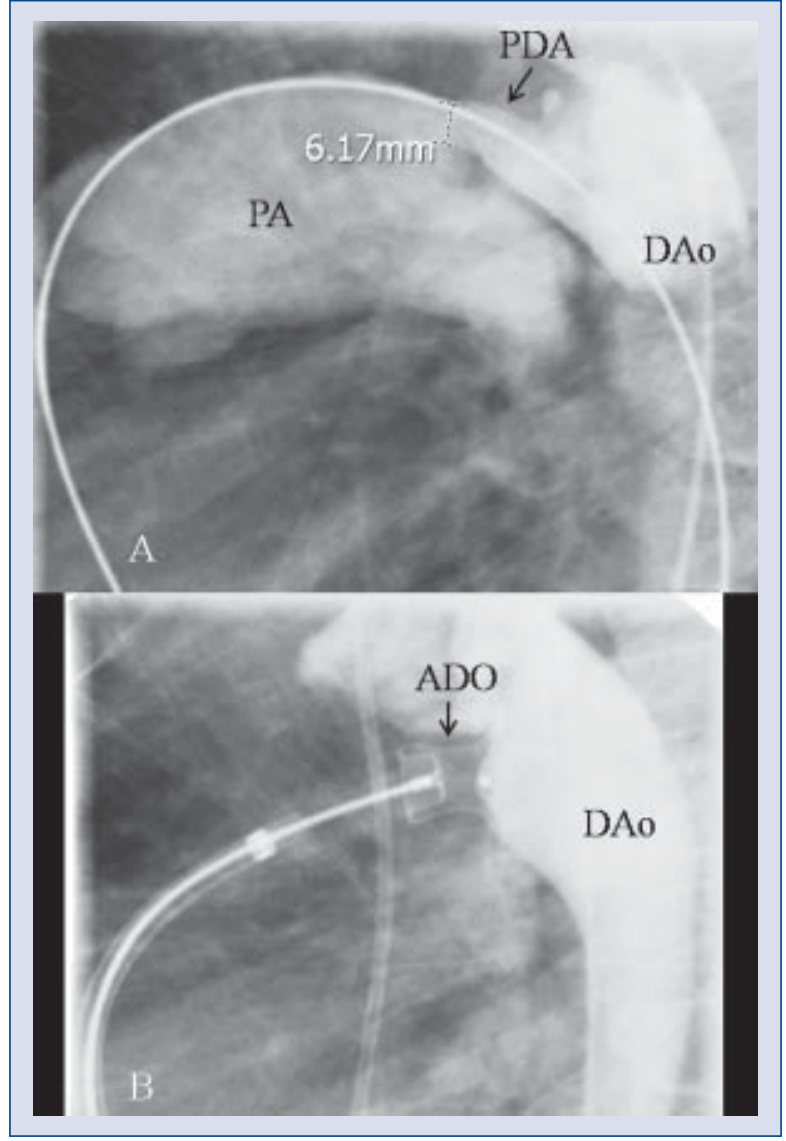

Figure 2. Angiography in the descending aorta (DAo) in patient 2 demonstrated contrast filled into pulmonary artery (PA) and size of patent ductus arteriosus (PDA) (A), and angiography after the Amplatzer ductal occlu$\operatorname{der}(A D O)$ demonstrated proper position of ADO in the PDA (B).

had PDA with moderate left to right shunt (calculated pulmonary to systemic blood flow, $\mathrm{QP}: \mathrm{QS}=1.8$ ), severe PAH ( $80 \%$ of systemic pressure), and high PVR (4.2 Wood units). His desaturation could be explained by a bi-directional shunt across the ASD due to pulmonary vascular disease. As a result of two levels of left to right shunt including ASD and PDA, this might promote high PVR. This might be explained in this case by his early age [6]. Nevertheless, after successful PDA device closure, his ASD was smaller and eventually closed. This led to resolution of his desaturation and partial improvement in his PAH.

Children with congenital heart defects and Down syndrome have particularly high PVR and a propensity towards early development of severe damage to the pulmonary vascular bed characterized by early progression of elevation of PVR probably due to insufficient thickness of the wall of the pulmonary artery [7]. In this report, cases 2 and 


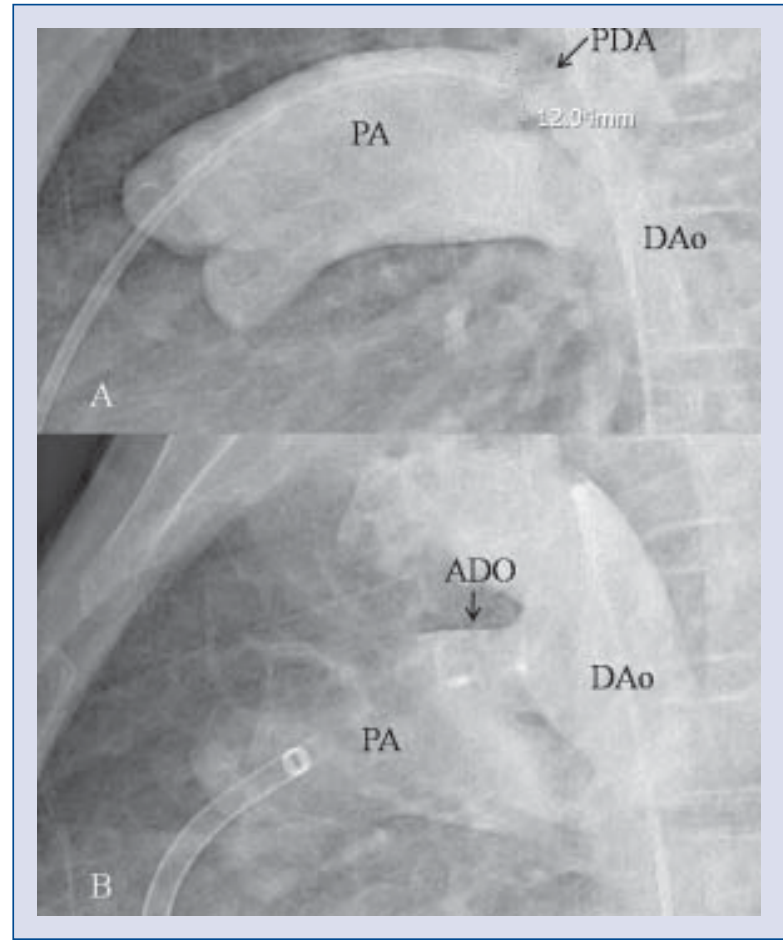

Figure 3. Angiography in the descending aorta (DAo) in patient 3 demonstrated contrast filled into pulmonary artery (PA) and size of patent ductus arteriosus (PDA) (A), and angiography after the Amplatzer ductal occluder (ADO) demonstrated proper position of ADO in the PDA with residual contrast filled via ADO into PA (B).

3 were Down syndrome. Case 2 had high PVR at room air oxygen ( $21 \%$ oxygen) with only trivial left to right shunt. His desaturation at room air oxygen (21\% oxygen) was caused by high PVR resulting in right to left shunt across PDA and differential cyanosis. However, when $100 \%$ oxygen was supplied, his left to right shunt was increased from 1.1 to 7 , his mean PAP decreased from 55 to $40 \mathrm{~mm} \mathrm{Hg}$, and his PVR decreased from 6.1 to 0.9 Wood units. This indicated pulmonary vasoreactivity of his PAH by oxygen [8]. Surgical closure of a PDA in older children associated with $\mathrm{PAH}$ is often challenging due to its thin and fragile wall, making conventional PDA ligation and/or division extremely high risk [9]. After successful PDA device closure, his desaturation was resolved and $\mathrm{PAH}$ was partially improved.

Case 3 had severe desaturation $\left(\mathrm{SaO}_{2} 70 \%\right)$ with very high PVR (25.5 Wood units) when he was only nine months old and it was concluded that he was inoperable at that time. This might be due to the delay in regression of PVR in Down syndrome. Surprisingly, his desaturation was improved and his $\mathrm{SaO}_{2}$ returned to $95 \%$. He underwent cardiac catheterization at the age of nine years which demonstrated large left to right shunt, but high PVR (5.7 Wood units), al- though his PVR was markedly decreased compared to the previous PVR when he was nine months old. The decision to close PDA in case 3 was delayed due to the high risk of the procedure. The option of surgery was to perform PDA closure under cardiopulmonary bypass when the risk of the surgery would be increased. Eventually, when he was 13 years old, we decided to use the ADO device to close a PDA in this case, since it was more advantageous to differentiate the reversibility of PAH and high PVR along with the use of oxygen and/or other medicine as pulmonary vasodilator tests. Moreover, the temporary occlusion of the PDA before it was completely deployed from its detachable cable wire was more reliable to assess the consequences of PDA closure and, thereby, to evaluate the reversibility of PAH and high PVR. Due to high PBF (calculated QP:QS 4.7), we elected not to perform pulmonary vasodilator test. However, after we placed the ADO to occlude the PDA before we detached ADO from delivery cable wire, PAP was decreased to $50 \mathrm{~mm} \mathrm{Hg}$. Nevertheless, using an ADO device to close a very large PDA, as in case 3 , may carry the probability of late embolization due to the lack of a disk in the pulmonary artery end. In such a scenario, the Amplatzer muscular ventricular septal defect occluder has been reported to successfully close the very large PDA instead [10].

In summary, we have reported three cases with a large PDA associated with PAH and desaturation, two of which were also associated with Down syndrome. The PAP could be partially improved after closure of the PDA, and desaturation in two cases was able to be resolved, while desaturation in the third case resolved spontaneously.

Conflict of interest: none declared

\section{References}

1. Beghetti M, Tissot C. Pulmonary arterial hypertension in congenital heart diseases. Semin Respir Crit Care Med, 2009; 30: 421-428.

2. Farber HW, Loscalzo J. Pulmonary arterial hypertension. N Engl J Med, 2004; 35: 1655-1665.

3. Masura J, Walsh KP, Thanopoulous B et al. Catheter closure of moderate- to large-sized patent ductus arteriosus using the new Amplatzer duct occluder: Immediate and short-term results. J Am Coll Cardiol, 1998; 3: 878-882.

4. Thanopoulos BD, Hakim FA, Hiari A et al. Patent ductus arteriosus equipment and technique. Amplatzer duct occluder: Intermediateterm follow-up and technical considerations. J Interv Cardiol, 2001; 14: 247-254.

5. Farber HW, Loscalzo J. Mechanism of disease: Pulmonary hypertension. Discov Med, 2005; 5: 80-87.

6. Adatia I, Kothari SS, Feinstein JA. Pulmonary hypertension associated with congenital heart disease: Pulmonary vascular disease. The global perspective. Chest, 2010; 137 (suppl.): 52-61.

7. Chi TPLKJ. The pulmonary vascular bed in children with Down syndrome. J Pediatr, 1975; 86: 533-538.

8. Oliveira EC, Amaral CF, Moura MA et al. Testing pulmonary vasoreactivity. J Bras Pneumol, 2008; 34: 838-844.

9. Kalavrouziotis G, Kourtesis A, Paphitis C, Azariades P. Closure of a large patent ductus arteriosus in children and adults with pulmonary hypertension. Hellenic J Cardiol, 2010; 51: 15-18.

10. Onorato E, Mbala-Mukendi M, Casilli F et al. Amplatzer Muscular VSD Occluder for catheter closure of a $20 \mathrm{~mm}$ hypertensive patent ductus arteriosus. A case report and literature review. Minerva Cardioangiol, 2004; 52: 219-223. 